\title{
ABSTRACTS FROM THE SCIENTIFIC AND TECHNICAL PRESS.
}

\author{
Issued by the \\ Directorates of Scientific Research and Technical Development, Air Ministry.
}

(Prepared by R.T.P.)

No. 48. OCTOBER, 1937.

Ground Effect-Theory and Practice. (E. Pistolesi, Pubblicazioni della R. Scuola d'Ingegneria di Pisa, Series VI, No. 26I, July, 1935, pp. 1-25. Translation in N.A.C.A. Tech. Memo. No. 828, June, I937.) (48/1 Italy.)

The author reviews very fully the previous work of Le Sueur, Datwyler, Muller, Glauert, Tani and Tomotika, and concludes by describing his own method for obtaining an approximate solution of the problem of ground interference.

Ground effect is still a controversial problem. There is a general concensus of opinion that the interference lowers the drag. As to the effect of the ground on maximum lift, both theory and experiment are inconclusive.

(Thirty-six references.)

Solution of Oseen's Equations for an Inclined Elliptic Cylinder in a Viscous Fluid. (D. Meksyn, Proc. Roy. Soc., Series A, Vol. 162, No. 909, I5/9/37, pp. 232-51.) (48/2 Great Britain.)

The equations of motion of a viscous fluid round an inclined elliptic cylinder have been solved by Oseen's approximation, the solution being expressed in Mathieu functions. The complete stream function for no slipping on the surface of the cylinder has been found and formulæ for lift and drag at very small Reynolds numbers $<4$ have been obtained. It remains for the future to extend the computations to larger values of Reynolds number.

Incidentally, an expression is found for Green's function for a plane externaI to an ellipse.

A maximum lift coefficient of about 1.7 is reached at an angle of incidence of $45^{\circ}$.

The drag increases continuously with increase of angle of incidence and the ratio of lift to drag has a maximum of about 0.22 at an incidence of $39^{\circ}$. Whilst no experimental results exist for such small Reynolds numbers the general type of curve is that for aerofoils.

Flow Through Granular Media. (B. A. Bakhmeteff and N. V. Feodoroff, J. App. Mech., Vol. 4, No. 3, Sept., 1937, pp. A. 97-104.) (48/3 U.S.A.)

Ever since Darcy's basic work on the mechanics of filtration, flow through porous media has been the abject of repeated research. Numerous and most valuable data on filtration coefficients have been gathered, the approach in recent years having been broadened by invoking the principle of dynamic similitude. So far, however, no general picture has been disclosed, such for example as made available for pipes by Osborne Reynolds and his successors. Systematic research 
was initiated accordingly with the object of possibly obtaining a comprehensive view of the phenomenon as a whole. This paper summarises the results of the first series of experiments, which deal with flow through media composed of uniform spherical bodies, for which lead shot varying in diameter from 0.0377 in. to $0.36 \mathrm{in}$. was used.

The device used permitted resistance slopes over $7: 1$, and the Reynolds characteristics were extended to $1.8 \times 10^{3}$. Under such conditions the whole series of the successive flow forms became evident. The initial Darcy type of flow with resistance proportional to the first power of the velocity was superseded by a zone where losses rapidly grew as an increasing power in the velocity $U^{\mathbf{n}}$, until in the higher ranges once more an apparently stable pattern with a constant exponent $n=\mathrm{I} .8$ was reached.

Recent Developments of the Theory of Turbulence. (H. L. Dryden, I. App. Mech., Vol. 4, No. 3, Sept., 1937, pp. A. 103-8.) (48/4 U.S.A.)

A brief account is given of the principal concepts which have been utilised in the formulation of theories of the turbulent motion of fluids prior to 1935 and the new approach originated by G. I. Taylor in that year is discussed.

A bibliography of $3^{\dot{1}}$ papers is included.

\section{Alternating Current Equipment for the Measurement of Fluctuations of Air Speed in Turbulent Flow. (W. C. Mock, Jr., N.A.C.A. Report No. 598, 1937.) (48/5 U.S.A.)}

Recent electrical and mechanical improvements have been made in the equipment developed at the National Bureau of Standards for the measurement of fluctuations of air speed in turbulent flow. Data useful in the design of similar equipment are presented. The design of rectified alternating current power supplies for such apparatus is treated briefly, and the effect of the power supplies on the performance of the equipment is discussed.

New Experimental Research on the Formation of Turbulent Flow in a Pipe. (H. Hahnemann, Forschung, Vol. 8, No. 5, Sept./Oct., 1937, pp. 236-7.) (48/6 Germany.)

The question of the transition from laminar to turbulent flow is important from a technical point of view. There are several theoretical and experimental investigations on this subject. The former gave a critical length for the disturbing waves; the latter showed that the intensity of the disturbance is also important. A photographic method (first developed by Schiller) is used to provide the numerical data. The paper shows the applications of this method to large initial disturbances, to large starting lengths and to rough tubes. The author obtains a curve giving the intensity of disturbance as a function of Reynolds number. This curve shows the change from laminar to turbulent flow.

Aerofoil Section Characteristics as Affected by Variations of the Reynolds Number. (E. N. Jacobs and A. Sherman, N.A.C.A. Report No. 586, 1937.) $(48 / 7$ U.S.A.)

An investigation of a systematically chosen representative group of related aerofoils was made in the N.A.C.A. variable density wind tunnel over a wide range of the Reynolds number extending well into the flight range. The tests were made to provide information from which the variations of aerofoil section characteristics with changes in the Reynolds number could be inferred and methods of allowing for these variations in practice could be determined. This work is one phase of an extensive and general aerofoil investigation being conducted in the variable density tunnel and extends the previously published researches concerning aerofoil characteristics as affected by variations in aerofoil profile determined at a single value of the Reynolds number. 
The object of this report is to provide means for making available as section characteristics at any free air value of the Reynolds number the variable density tunnel aerofoil data previously published. Accordingly, the various corrections involved in deriving more accurate aerofoil section characteristics than those heretofore employed are first considered at length and the corrections for turbulence are explained. An appendix is included that covers the results of an investigation of certain consistent errors presented in test results from the variable density tunnel. The origin and nature of scale effects are discussed and the aerofoil scale effect data are analysed. Finally, methods are given of allowing for scale effects on aerofoil section characteristics in practice within ordinary limits of accuracy for the application of variable density tunnel aerofoil data to flight problems.

\section{The Effect of Curvature on the Transition from Laminar to Turbulent Boundary Layer. (M. Clauser and F. Clauser, N.A.C.A. Tech. Note No. 6r 3, Sept., 1937.) (48/8 U.S.A.)}

In the flow over the upper surface of a wing, a discrepancy between the predicted and actual point of transition from laminar to turbulent boundary layer had been found. This effect may be due to the comparatively small radius of curvature of the upper surface of the wing. The present tests were undertaken to investigate this effect.

As no available channel was suitable for this work, a new channel with two working sections was built. One working section had a wall with a 20 -inch radius of curvature and the other section had a flat wall.

Three types of measurement were made: $(a)$ Traverses were made with a total head tube to determine the character of the boundary layer at various Reynolds numbers. (b) The turbulence distribution in the boundary layer was investigated by means of a hot wire and a vacuum tube amplifier. (c) A similar investigation of the mean velocity distribution in the boundary layer was made by a hot wire anemometer.

It was found that, by using an abbreviated form of the turbulence level traverses, critical Reynolds numbers for the transitions could be established. These critical Reynolds numbers are plotted as a function of the ratio of the distance of the transition from the leading edge of the plate to the radius of curvature of the plate for both the convex and concave side of the plate. The experimental points for the convex and concave side of the sheet are consistent with each other. The variation is of such an order of magnitude that the curvature ordinarily used on the upper surface of an aeroplane wing might double the critical Reynolds number.

The Herrick Vertaplane. (R. H. McClarren, Aviation, Vol. 36, No. 9, Sept., I937, p. 53.) (48/9 U.S.A.)

In appearance the Herrick vertaplane resembles a conventional biplane. The upper wing is symmetrical about the centre line and is devised so that it can be released from the fixed position and started to rotate about a vertical axis. Autorotation is then maintained, the object being to combine the slow landing characteristics of the autogiro with the high speed and efficiency of the normal fixed wing aircraft. One of the difficulties is obviously to develop a profile for the upper wing which will autorotate and at the same time be reasonably efficient in the fixed position. It is claimed that in its present more or less experimental form the machine has a top speed of roo m.p.h. (wing fixed) and a landing speed (wing rotating) below 30 m.p.h. Detailed performance figures are not available, but the following principal characteristics are given:-

Span (upper wing), $24 \mathrm{ft}$. Area, 70 sq. ft.

Span (lower wing), $28 \mathrm{ft}$. Area, 100 sq. ft.

Disc area, upper wing, $45^{2}$ sq. $\mathrm{ft}$.

Engine, Kinner B.5, I 25 b.h.p.

Gross weight, 1,7 oolb. 
Airscrew Blade Vibration. (B. C. Carter, J.R. Aeron. Soc., Vol. 41, No. $3^{21}$, Sept., 1937, pp. 749-790.). (48/10 Great Britain.)

During development of solid metal airscrews in the U.S.A. many vibration failures occurred and various investigations have bèen made there and elsewhere with a view to overcoming such troubles. The problem is to avoid airscrew failures while keeping weight as low as possible; its solution involves mathematical analysis, further development of experimental methods, and investigations in relation to particular combinations of engine and airscrew.

Coming to the subject as an extension of crankshaft torsional vibration investigations, the author, in association with his colleagues at the Royal Aircraft Establishment, has made extensions in the mathematical treatment which serve to clarify ideas concerning the modes of vibration that may occur and also to form a new basis for experimental investigation. The essentials of this treatment are described in the paper, to which there is an appendix giving a brief mathematical examination of flexural vibration of elastically encastred blades.

Effect of Slipstream on the Longitudinal Stability of a Low Wing Monoplane. (C. M. Bolstar, J. Aer. Sci., Vol. 4, No. Io, August, 1937, pp. 41 1-416.) (48/1 I U.S.A.)

I. Calculated values of lift coefficient with slipstream agree closely, with experimental " power on " results.

2. Calculated values of the moment coefficient due to wing and fuselage with slipstream do not agree with experimental values quantitatively; the observed slipstream influence is approximately 1.7 times the calculated value.

3. Slipstream improves the stability of the wing and fuselage alone in a low wing monoplane.

4. Slipstream decreases the slope of the tail moment coefficient curves as amount of power is increased.

5. Slipstream increases the moment caused by a movement of elevator from neutral to either an up or down position.

6. Near the stall, slipstream creates an unstable region in the tail moment coefficient curves, when the horizontal stabiliser is on or near the thrust line. This disappears if the stabiliser is located relatively as high as the top position used in this investigation. Presumably higher positions would also be satisfactory.

7. With split flaps set at $45^{\circ}$, slipstream decreases the stability in power on gliding flight. The effect is less when the stabiliser is mounted in the top position.

Experiments with Automatic Flaps. (R. F. Hall, J. Aer. Sci., Vol. 4, No. 10, August, 1937, pp. 427-33.) (48/1 2 U.S.A.)

This paper describes wind tunnel research and flight testing of a high lift wing development by the author. The wing has a longitudinal passage-way with a floating vane controlled opening at the under side, and principally up moving ailerons above full span automatically operated flaps. The vane, which is usually independent of the flap, only opens to by-pass air for discharge between the ailerons and flap in ordinary flight when the flap is lowered. Ailerons may be correlated to depress slightly with the flap.

The passage-way increases lift, especially for small displacement angles of the flap, and improves control during slow speed flight and when taxying. Automatic flap operation is obtained by the application of initial force to produce moments at the flap to balance air hinge moments. Lateral control through principally upward movement of the aileron is satisfactory if system instability at high speed and large operating forces at slow speed are prevented. This is accomplished by an aileron lower paddle which aids response. 
Free-Spinning Wind Tunnel Tests of a Low Wing Monoplane with Systematic Changes in Wings and Tails. I. Basic Loading. (O. Seidman and A. I. Neihouse, N.A.C.A. Tech. Note No. 608, Aug., I937.) (48/13 U.S.A.)

A series of tests was made in the N.A.C.A. free-spinning tunnel to determine the effect of systematic changes in wing and tail arrangement upon steady spinning and recovery characteristics of a conventional low wing monoplane model for a basic loading condition. Eight wings and three tails, covering a wide range of aerodynamic characteristics, were independently ballasted so as to be interchangeable with no change in mass distribution. For each of the 24 wing tail combinations, observations were made of steady spins for four control settings and of recoveries for five control manipulations. The results are presented in the form of charts comparing the spin characteristics. The results showed that, with a poor tail arrangement, wing plan form and tip shape had considerable effect on the spinning characteristics. A wing with rectangular plan form gave noticeably steeper spins and faster recoveries than the same wing with army tips. Poorest recoveries were obtained for a wing with 5:2 plan form taper and no thickness taper; rapid recoveries were obtained with a wing having $2: 1$ taper in both plan form and thickness. For all the wings tested, satisfactory recoveries could be obtained by the use of a tail with a deepened fuselage and a raised stabiliser. Holding the elevators up resulted in the steepest spins from which, by reversal of both controls, the most rapid recoveries were obtained. Steepest spins were generally, though not always, associated with most rapid recovery, but there appeared to be no relation between the sideslip of the steady spin and the turns required for recovery.

Considerations Affecting the Additional Weight Required in Mass Balance of Ailerons. (W. S. Diehl, N.A.C.A. Tech. Note No. 609, Aug., 1937.) (48/14 U.S.A.)

This paper is essentially a consideration of mass balance of ailerons from a preliminary design standpoint, in which the extra weight of the mass counterbalance is the most important phase of the problem. Equations are developed for the required balance weight for a simple aileron and this weight is correlated with the mass balance coefficient. It is concluded that the location of the c.g. of the basic aileron is of paramount importance and that complete mass balance imposes no great weight penalty if the aileron is designed to have its c.g. inherently near to the hinge axis.

Wind Tunnel Tests on Autorotation. (Inter. Aria., No. $47^{2}, 18 / 9 / 37$, p. 5.) (48/15 Switzerland.)

According to experiments by Haller at Zurich, the tail unit of an aeroplane does not, as previously assumed, exercise a braking effect on the spin, but will contribute a spinning moment quite independently of the wing system. Whilst, however, the spin of the wing system is due to a decrease in lift with an increase in $a$, the spinning produced by the tail unit at large angles of incidence is due to peculiar effects of " oblique attack," the portion of the rudder above the elevator experiencing aerodynamic force increasing the spin. The portion below the elevator exercises a braking effect which is, however, usually not sufficient to prevent autorotation.

Honeycomb Metal Wing Features New Wight Passenger Aeroplane. (W. F. Sherman, Iron Age; Vol. I40; No. I. J. Frank. Inst., Vol. 224, No. 3, Sept., r937, p. 282.) (48/16 U.S.A.)

The wing has neither conventional spars (beams) nor ribs (fore and aft formers). Instead it is built up of a series of rectangular tubes, or cells, which provide the equivalent of eight spars. Construction consists of the assembly of a number of spanwise webs of thin sheet aluminium alloy, flanged for assembly purposes, 
and lightened by means of punched, flanged holes. Bottom and top covering, alclad sheet, is riveted to the internal structure. This arrangement produces 27 uniformly tapered tubes or cells extending outward to the wing tip. Fully cantilever, this wing structure has no supports outside in the airstream, all bending, drag and torque loads being carried by the internal structure and metal covering.

Air Propellers in Yaw. (E. P. Lesley, G. F. Worley and S. Moy, N.A.C.A. Report No. 597, 1937.) (48/17 U.S.A.)

Tests of a 3 -foot model propeller at four pitch settings and at $0^{\circ}, 10^{\circ}, 20^{\circ}$ and $30^{\circ}$ yaw were made at Stanford University. In addition, the usual propeller coefficients, cross wind and vertical forces, and yawing, pitching and rolling moments were determined about axes having their origin at the intersection of the blade axis and the axis rotation.

The tests showed that the maximum efficiency was reduced only slightly for angles of yaw up to $10^{\circ}$, but that at $30^{\circ}$ yaw the loss in efficiency was about Io per cent. In all cases the cross wind force was found to be greater than the cross wind component of the axial thrust. With a yawed propeller an appreciable thrust was found for $V / n D$ corresponding to zero thrust at zero yaw. Yawing a propeller was found to induce a pitching moment that increased in magnitude with yaw.

An Analysis of the Factors that Determine the Periodic Twist of an Autogiro Rotor Blade, with a Comparison of Predicted and Measured Results. (J. B. Wheatley, N.A.C.A. Report No. $600,1937$.$) (48/18 U.S.A.)$

An analysis is presented of the factors that determine the periodic twist of a rotor blade under the action of the air forces on it. The results of the analysis show that the Fourier coefficients of the twist are linear expressions involving only the tip speed ratio, the pitch setting, the inflow coefficient, the pitching moment coefficient of the blade aerofoil section, and the physical characteristics of the rotor blade and machine. The validity of the analysis was examined by using it to predict the twist of a rotor whose twist characteristics had previously been measured in flight. The agreement between the calculated and experimental results was satisfactory. An examination of the assumption used in the analysis - -that the twist is a linear function of the radius-disclosed that the approximation introduced no appreciable error. From this examination, a formula for the torsional rigidity of the rotor blade was derived.

Wind Tunnel Investigation of Wings with Ordinary Ailerons and Full Span External Aerofoil Flaps. (R. C. Platt and J. A. Shortal, N.A.C.A. Report No. 603, 1937.) (48/19 U.S.A.)

An investigation was carried out in the N.A.C.A. 7 by 10 -foot wind tunnel of an N.A.C.A. 23 ,or 2 aerofoil equipped, first, with a full span N.A.C.A. 23, or 2 external aerofoil flap having a chord 0.20 of the main aerofoil chord and with a full-span aileron with a chord 0.12 of the main aerofoil chord on the trailing edge of the main aerofoil and equipped, second, with a 0.30 chord full span N.A.C.A. 23 , or 2 external aerofoil flap and a 0.13 chord full span aileron. The results are arranged in three groups, the first two of which deal with the aerofoil characteristics of the two aerofoil flap combinations and with the lateral control characteristics of the aerofoil flap aileron combinations. The third group of tests deals with several means of balancing ailerons mounted on a special large chord N.A.C.A. 23 ,or 2 aerofoil model with and without a 0.20 chord N.A.C.A. 23 оr 2 external aerofoil flap. The tests included an ordinary aileron, a curtained-nose balance, a Frise balance, and a tab.

The results obtained for the $0.30 c_{\mathrm{w}}$ flap verify the conclusion made from previous tests of the $0.20 c_{w}$ flap combination, namely, that external aerofoil flaps 
applied to the N.A.C.A. 230 aerofoil sections give characteristics more favourable to speed range, to low power requirements in flight at high lift coefficients, and to low flap-operating moments than do other types of flap in general use. The aerodynamic advantages of this aileron flap combination appear to outweigh probable design difficulties.

Spinning Characteristics of Wings III-A Rectangular and a Tapered Clarke $Y$ Monoplane Wing with Rounded Tips. (M. J. Bamber and R. O. House, N.A.C.A. Tech. Nọte No. 612, Sept., 1937.) (48/20 U.S.A.)

An investigation was made to determine the spinning characteristics of Clarke $Y$ monoplane wings with different plan forms. A rectangular wing and a wing tapered $5: 2$, both with rounded tips, were tested on the N.A.C.A. spinning balance in the 5 -foot vertical wind tunnel.

The aerodynamic characteristics of the models and a prediction of the angles of sideslip for steady spins are given. An estimate of the yawing moment that must be furnished by the parts of the aeroplane to balance the inertia couples and wing yawing moment for spinning equilibrium is also included. The effects on the spin of changes in plan form and of variation of some of the important parameters are discussed and the results are compared with those for a rectangular wing with square tips.

It is concluded that for a conventional monoplane using Clarke $Y$ wings: The sideslip will be algebraically larger for the wing with the rounded tip than for the wing with the square tip and will be largest for the tapered wing; the effect of plan form on the spin will vary with the type of aeroplane; and the provision of a yawing moment coefficient of -0.025 (i.e., opposing the spin) by the tail, fuselage and interference effects will insure against the attainment of equilibrium in a steady spin for any of the plan forms tested and for any of the parameters used in the analysis.

Modern Development in Anti-Aircraft Guns (from the French). (Luftwehr, Vol. 4, No. 3, March, I937, p. I 20.) (48/2 I France.)

A mechanical type of detonator is to be preferred to the chemical since the latter is too much affected by the altitude. Recently, a device has been perfected for setting the detonator to the required altitude when the shell is already in the gun barrel. From statistics of the years $19^{17-18}$ it appears that between 3,000 and 7,000 rounds had to be fired to bring down one enemy aircraft. It is interesting to note that French and German statistics are in fair agreement in giving between three and four guns in action for every hit.

Some Notes on Aerial Warfare in Spain. (Revue de l'Armee de 1'Air, No. 96, July, 1937, p. 836.) (48/22 France.)

I. Fabric covered wings have been destroyed by the air concussion of bombs exploding I5 m. away. All-metal machines suffer less, it is however essential in their case that the fuselage be fitted with vent holes which release the compressed air due to a bomb exploding in the vicinity.

(For the same reason hangar doors must be left open and if at all possible, openings at opposite ends of the building should be provided.)

2. Fuel storage tanks $4 \mathrm{~m}$. underground (earth only) and covered by sand bags ( $\mathrm{m}$. 5o) have withstood direct hits by $200 \mathrm{~kg}$. bombs without trouble.

3. Alternate layers of earth and concrete offer more resistance to bombs than the same total thickness in solid concrete.

4. Incendiary bombs have produced very little effect when used against aerodromes and hangars. Even when used against towns (Madrid, etc.) the results have not come up to expectations. 
Aerial Warfare in Spain. (Revue de l'Armee de 1'Air, No. 91, Feb., 1937, pp. 185-198.) (48/23 France.)

The article gives some details of the French, Russian, Italian and German aircraft in use up to the end of last year.

The following conclusions concerning air fighting are of interest :-

I. Twin-engined bombers are very vulnerable to right-angled as well as tail attack. The former method of attack, if carried out simultaneously from both sides, is specially difficult to repel. A bomber formation is very far from being a "flying fortress" and requires protection by accompanying fighters.

2. The Germans specialise in low altitude attack working in close co-operation with infantry. At altitudes below $10, \infty 00$ feet, the non-supercharged engine gives a better performance and the aircraft is more mancuvrable than the 1,000 b.h.p. high performance fighter.

3. Steel fuselage combined with plywood or fabric wing covering is preferable to all-metal construction, since it can be repaired more easily.

4. In actual service quantity counts more than quality of material, provided the pilots are well trained.

The Heat Transfer Processes in Air-Cooled Engines. (B. Pinkel, J. Aer. Sci., Vol. 4, No. 1o, August, 1937, pp. 403-9.) (48/24 U.S.A.)

From a consideration of heat transfer theory, expressions have been obtained for the rate of heat transfer from the engine gases to the cylinder walls and from the cylinder walls to the cooling air. These expressions contain several empirical constants, values for which were obtained from test data for a Pratt and Whitney $\mathrm{I}, 34^{\circ}-\mathrm{H}$ cylinder. The test data were obtained by the N.A.C.A. at its engine laboratories at Langley Field. From these expressions, equations are obtained for the average cylinder head and barrel temperatures as functions of the fundamental engine and cooling variables. Although the maximum head and barrel temperatures are the limiting factors, a good approximation to the variation in the maximum temperatures may be obtained from the variation in the respective average temperatures.

The average head and barrel temperatures calculated from the equations were found to check experimental values with a good degree of accuracy.

Effect of Air Entry Angle on Performance of a Two-Stroke Cycle Compression Ignition Engine. (S. L. Earle and F. J. Dutee, N.A.C.A. Tech. Note No. 6ro, August, 1937.) (48/25 U.S.A.)

An investigation was made to determine the effect of variations in the horizontal and vertical air entry angles on the performance characteristics of a singlecylinder two-stroke cycle compression ignition test engine. Performance data were obtained over a wide range of engine speed, scavenging pressure, fuel quantity, and injection advance angle with the optimum guide vanes. Friction and blower power curves are included for calculating the indicated and net performances.

The Determination of Ratings for Transport Aircraft Engines. (R. F. Gagg, J.S.A.E., Vol. 41, No. 3, Sept., 1937, pp. 400-4.) (48/26 U.S.A.)

The objective in determining an engine rating is to establish the limiting values for the variables in operating procedure which permit a maximum of utility in power output and economy of fuel consistent with requirements for safety and durability in the class of service for which the engine is intended. The obvious safety requirement is that no interruptions to service shall occur due to engine trouble when operations are conducted in the manner established by the rating tests. 
This paper consists of a discussion of testing methods to be used for the determination of engine ratings, and some suggestions for the adoption of a uniform procedure. Standardisation of engine rating procedure is thoroughly in accordance with the established policy of the American aircraft industry as a means of insuring a maximum of safety to air transport passengers.

American aircraft and engine testing requirements are more rigorous than those of many other countries, and it is for this reason that American products have established a world-wide reputation for safety and durability. If this leadership is to be maintained, technical standardisation and advancement must be synchronised and co-ordinated so that each activity supplements the other.

\section{Power Plant Trends. (G. J. Mead, J.S.A.E., Vol. 4I, No. 3, Sept., 1937, Papers in Digest, p. 29.) (48/27 U.S.A.)}

The rapid increase in the size of our air transports, as well as the requirements for higher cruising speeds, forewarn of the need of power plants of decidedly greater power. The further development of the existing standard types may be relied upon to ultimately provide at least $5^{\circ}$ per cent. greater output. There is, however, definite evidence now of the need of engines of even greater power in the period immediately ahead, which need has focussed attention on other types in which additional displacement may be provided through the employment of a greater number of cylinders.

Studies indicate that there is an opportunity of reducing the power plant drag sufficiently to effect a saving in fuel at least as great as is promised by further improvement in specific consumption. For this reason the form and location of the new power plants, as well as the method chosen for cooling them, will be dictated largely by the resulting effect on operating costs. It seems likely that two new engine types will result in which twice as many cylinders may be employed as is now common practice and proportionately greater power will be provided.

The problems involved are decidedly more complex than hitherto have been encountered, but the industry is now equipped with both personnel and experience to deal effectively with them. For this reason, there is little question that power plant development will keep pace with the requirements.

An Investigation of Mica Spark Plugs. (M. F. Peters, H. K. King and J. P. Boston, J.S.A.E., Vol. 41, No. 3, September, 1937, Papers in Digest, p. 29.) (48/28 U.S.A.)

A simplified mathematical analysis of the heat flow in mica spark plugs and in the adjacent ignition cable is given in this paper, together with curves showing various relationships of temperature and thermal conductivity. The related question of thermal expansion also is considered. Some of the more important electrical characteristics such as capacitance, potential gradients, corona, and altitude flash-over, are discussed.

An experimental section gives a design for a mica plug and a description of experimental types with data on the more important aspects of performance. Methods of testing are discussed.

The In-Line Air-Cooled Aircraft Engine. (A. T. Gregory, J.S.A.E., Vol. 4I, No. 3, September, 1937, Papers in Digest, p. 30.) (48/29 U.S.A.)

With engine outputs continually going up it is worthy to note that the in-line air-cooled engine possesses certain inherent characteristics which make it particularly suitable as an aircraft engine of high output.

Satisfactory cooling of this type of engine has been obtained at higher rated specific outputs than have yet been achieved in any other kind of air-cooled engine. 
A type of valve gear can be used which, in addition to being suitable for high speed operation, permits long periods of operation without the necessity for checking valve clearances.

The lubrication of this type of engine appears to be less of a problem than that of the slower speed radials.

Smoothness of operation and relative quietness at high speed not only afford comfort to pilots and passengers, but also affect favourably the life of both engine and aeroplane.

The cowling of the in-line engine is relatively simple and permits excellent visibility combined with the possibility of reduced drag.

Specific weights of in-line engines compare favourably with other engines of equal horse-power. As specific outputs are increased the in-line engine should gain a weight advantage over other types.

Altitude and Other Variables Affecting Flame Speed in the Otto Cycle Engine.

(C. L. Bouchard, C. F. Taylor and E. S. Taylor, J.S.A.E., Vol. 4I,

No. 3, Sept., 1937, Papers in Digest, p. 3o.) (48/30 U.S.A.)

In the investigations reported in this paper flame trace photographs were taken on a moving film through a glass window slot in an engine cylinder to show the effects of various operating conditions on the rate of flame travel across the combustion chamber. The tests were made with a small L-head singlecylinder engine and the technique is similar to that used by Withrow and Boyd in flame studies reported in $193 \mathrm{I}$.

The present investigation covers a considerable range of operating conditions, including altitude, with and without supercharging, inlet temperature, humidity of the intake air, engine speed, ignition timing, and fuel-air ratio.

In general, the results show that flame speed decreases with increasing altitude in an unsupercharged engine. Either supercharging or reducing the exhaust pressure with inlet pressure constant tends to increase flame speed. The flame speed decreases with increasing inlet temperature and with increasing humidity. Observations of the effects of revolutions per minute, fuel-air ratio, and spark advance confirm the results of previous investigations.

Spark Advance Indicator. (J. R. Macgregor and K. Eldredge, J.S.A.E., Vol. 4I, No. 3, Sept., I937, Papers in Digest, p. $3^{8 .}$ ) (48/3 I U.S.A.)

In the study and operation of mechanisms there are many instances where the interval ratio of cyclic events requires evaluation. In research involving the use of petrol engines, such a device fulfils a long-felt want in providing a means for instantaneously and continuously indicating spark advance.

The spark advance indicator has been developed for road test work and is designed so that connections are made readily to the engine by electrical means; backlash and other errors inherent in mechanical drives are thereby eliminated. The spark advance, without regard to the engine speed, is indicated on a meter placed at any convenient location, and the indicated values are in terms of degrees ahead of a predetermined datum point, such as top centre.

The Mercedes Benz DB-600-The First German 1,000 b.h.p. Aero Engine. (Autom. Tech. Zeit., Vol. 40, No. I7, Io/9/37, p. 441.) (48/32 Germany.)

This engine made its first public appearance at the International Meeting at Zurich this year, where it scored outstanding successes.

Leading Characteristics.-12-cylinder inverted V $\left(60^{\circ}\right.$, liquid-cooled); bore, I $50 \mathrm{~mm}$. ; stroke, I60; comp. ratio, 6.5 ; fuel, 87 octane.

The carburettor is of the pressure type (on the delivery end of supercharger) and consists of a twin-float chamber feeding four separate jet units (one to each group of three cylinders). 
The single-stage supercharger supplies air at 1.22 atm. for ground boost (engine model A/B).

The supercharger driving shaft is at right angles to the engine crankshaft and the plane of rotation of the impeller is then parallel to the longitudinal axis of the engine.

\begin{tabular}{|c|c|c|c|c|c|}
\hline \multicolumn{6}{|c|}{ Performance, } \\
\hline $\begin{array}{c}\text { Height. } \\
\text { O }\end{array}$ & $\begin{array}{l}\text { r.p.m. } \\
2,400\end{array}$ & $\begin{array}{l}\text { b.h.p. } \\
1, \infty \infty 0\end{array}$ & $\begin{array}{c}\text { Fuel } \\
\text { gm./b.h.p. } \\
\text { hour. } \\
235\end{array}$ & $\underset{\substack{\text { Oil } \\
\text { hour.jb.h.p. }}}{-}$ & $\begin{array}{l}\text { Remarks. } \\
5 \text { minutes. }\end{array}$ \\
\hline o & 2,300 & 900 & $23^{\circ}$ & - & \\
\hline 0 & 2,200 & 800 & 225 & 8 & Continuous \\
\hline
\end{tabular}

\begin{tabular}{|c|c|c|c|c|c|}
\hline Height. & r.p.m. & b.h.p. & $\begin{array}{c}\text { Fuel } \\
\text { gm./b.h.p. } \\
\text { hour. }\end{array}$ & $\begin{array}{c}\text { Oil } \\
\text { gum./b,h.p, } \\
\text { hour. }\end{array}$ & Remarks. \\
\hline o & 2,300 & $95^{\circ}$ & - & - & I minute. \\
\hline I $3,000 \mathrm{ft}$. & 2,400 & 910 & 240 & - & 5 minutes. \\
\hline I $3,000 \mathrm{ft}$. & 2,300 & $85^{\circ}$ & 220 & - & $30 \quad$, \\
\hline I $3,000 \mathrm{ft}$ & 2,200 & 800 & 215 & 8 & Continuous \\
\hline
\end{tabular}

Cooling Tests of a Single-Row Radial Engine with Several N.A.C.A. Cowlings. (M. J. Brevoort, G. W. Stickle and H. H. Ellerbrock, N.A.C.A. Report No. 596, 1937.) (48/33 U.S.A.)

The cooling of a single-row radial air-cooled engine using several cowling arrangements has been studied in the N.A.C.A. 2o-foot wind tunnel. The results show the effect of the propeller and several cowling arrangements on cooling for various values of the indicated horse-power in the climb condition. A table giving comparative performance of the various cowling arrangements is presented. The dependence of temperature on indicated horse-power and pressure drop across the baffles is shown by charts. Other charts show the limiting indicated horsepower against the pressure drop across the engine and the heat dissipated at various values of the indicated horse-power.

Oiliness and Wear. (G. L. Neely, J.S.A.E., Vol. 4I, No. 3, Sept., 1937, Papers in Digest, p. 3o.) (48/34 U.S.A.)

The purpose of this paper is to call attention to the need for fundamental wear investigations and to show that wear does not correlate with oiliness.

A testing machine suitable for measuring both friction and wear is described. The machine, which is a modification of one previously reported by the author, uses two sets of frictional surfaces-one in the form of a track having two concentric rails and the other consisting of three small buttons with recessed centres and flat tracks on the outer edges. An important feature of the machine is that the rubbing surfaces are maintained automatically at an almost uniform degree of surface smoothness by the lapping action produced by the combined rotating and sliding motion of the buttons.

The results presented lead to the following conclusions within the thin film range investigated:-

(I) Both wear and friction vary directly with load.

(2) Total wear reaches a maximum, in some cases, at one particular speed, whereas wear rate (metal removed per unit of linear surface rubbed) decreases generally as speed is increased.

(3) No direct relation exists between wear and friction.

A new term " coefficient of wear," relating wear rate and load is proposed. 
High Pressure Viscosity as an Explanation for Apparent Oiliness. (H. A. Everett, J.S.A.E., Vol. 41, No. 3, Sept., 1937, Papers in Digest, p. 30.) (48/35 U.S.A.)

Oils from three different crudes, matched as to initial viscosity, but with widely different viscosity indexes, gave markedly different values when tested in an oiliness machine.

As viscosity index indicates temperature effects only, the effect of pressure on viscosity was investigated in a high pressure viscometer. For each oil viscosities at pressures up to $50,000 \mathrm{lb}$. per $\mathrm{sq}$. in. were obtained for three different temperatures. From these data characteristic curves were plotted giving complete pressure, viscosity, temperature relations. Using such curves it was possible to trace the changes in viscosity which each oil underwent in its passage through the bearing and obtain an estimate for equivalent viscosity. When this study was made, the different so-called " oiliness" effects were shown to be but the normal effect of the true viscosity actually existing in the oil film.

The paper calls attention to the need for intormation on the influence of pressure on viscosity as well as of temperature on viscosity when comparing or predicting the performance of oils in service bearings.

A Springless Bouncing Pin Indicator. 'E. Bartholomew and C. Walcutt, J.S.A.E., Vol. 4r, No. 3, Sept., 1937, Papers in Digest, p. 3o.) $\left(48 / 3^{6}\right.$ U.S.A.)

Carbon accumulation, atmospheric humidity, adjustment of bouncing pin indicator, and knock intensity are four important variables in knock testing which at present are not very well standardised. A recently developed springless bouncing pin indicator appears to offer the possibility of considerably improved control of the last two.

The instrument incorporates a diaphragm identical to that used in the conventional bouncing pin indicator and a modified pin proper, the lower end of which is separated from the diaphragm by a gap which is subject to control by a micrometer adjustment. The contact points are highly resistant to corrosion and have high magnetic permeability. One is carried on the upper end of the pin, about which is wound a coil of wire in series with the contact points. The upper contact point, of quite light weight, is free to move upward without restraint. The gap between the two points also is controlled by a micrometer screw, the two micrometer screws being the only adjustments provided. Initial contact of the points energises the magnetic coil and holds the points in good electrical contact until separation is effected by the falling of the pin. The motion of the pin is substantially that of a freely projected body and results in greater sensitivity than that given by the conventional indicator, together with good stability.

Modern Trends in Motor Oils. (G. M. Maverick, J.S.A.E., Vol. 4I, No. 3, Sept., 1937, Papers in Digest, p. 42.) (48/37 U.S.A.)

In lubricating the compact high speed motors of to-day throughout all the abuse that they are obliged to take, an oil is good only if it rates high in the following features:-Low consumption; must allow winter starting with the least effort; must flow instantly on the coldest start; must not form sludge, stick rings, or leave excessive carbon on vaporisation; must withstand greater loads and higher speeds; and must not break down with the formation of products corrosive to bearing materials.

During the past few years there has been a trend toward making the higher grades of oils by extensively refining a selected petroleum fraction to furnish a clean high boiling base and then adding relatively small quantities of synthesised materials to impart the desired final properties. The addition agents now available and widely used include materials for increasing viscosity and viscosity 
index; for reducing pour points; for giving greater oiliness; and for increasing resistance to oxidation and preventing bearing corrosion.

This paper points out some of the advantages and dangers in the use of such addition agents, with conclusions backed by test results on some of these materials.

The American Picture-Diesel Fuel Research. (C. G. A. Rosen, J.S.A.E., Vol. 4I, No. 3, Sept., 1937, pp. 393-9.) (48/38 U.S.A.)

Primarily intended as a discussion and amplification of the paper of Messrs. Boerlage and Broeze, presented at the April, 1936, meeting of the American Chemical Society, ${ }^{*}$ this paper is limited to the pre-combustion chamber type of Diesel engine burning California base fuels.

The paper describes investigations of ignition quality, fuel spray characteristics, and injection phenomena by means of a single-cylinder test unit fitted with a quartz observation window, stroboscope, timing disc and phase changing device.

A discussion of the products of incomplete combustion as influenced by compounded lubricants and ring belt temperatures concludes the paper.

Special Fuel for Internal Combustion Engines. (U.S. Patent 2,087,616, 2ott. July, 1937.) (M. Mueller-Cunradi and M. Otto to I.G. Farbenindustrie A-G., Chem Absts., Vol. 31, No. I7, 10/9/37, p. 6445.) (48/39 U.S.A.)

For avoiding risks of the fuel supply catching fire in operating an internal combustion engine, there is used as a fuel source a polymerisable combustible hydrocarbon material containing $\mathrm{C}$ and $\mathrm{H}$ only and bound in the form of a nonexplosive polymer having a mean molecular weight above 400 and capable of being depolymerised on heating, such as isobutylene or hydrorubber polymers, and on its way to the engine the material is fed through a heated passage to effect its depolymerisation.

Apparatus is described.

The Problem of Bearing Friction. (G. Vogelpoh1, V.D.I.-Forschungsheft, No. 386, Sept.-Oct., I937, pp. I-28.) (48/40 Germany.)

The hydrodynamic equations of the lubricating film contain the following quantities (which define the lubricant) as a function of the film temperature :-
I. Viscosity.
2. Density.
3. Specific heat.
4. Thermal conductivity.

The pressure distribution for a given clearance is such that the friction losses are a minimum. Using this fundamental principle, the author obtains new solutions for the bearing of finite width by the method of variation. The type of flow in the film is illustrated by means of model experiments and a theoretical investigation of the temperature distribution in the two-dimensional case is carried out. It appears that for the same geometrical form of the film, the load capacity of the bearing is greater for oils with a flat viscosity/temperature curve.

The author proposes a new coefficient for estimating lubricating value of an oil. This coefficient is defined as $\beta / \gamma c$ where

$$
\begin{aligned}
& \beta=\text { gradient of viscosity/temperature curve. } \\
& \gamma=\text { density of oil. } \\
& c=\text { specific heat of oil. }
\end{aligned}
$$

It appears that many phenomena associated with so-called " boundary" or " mixed" lubrication can be accounted for by. heat generated in the metal surfaces directly as opposed to heat generated in the oil film as is the case in true fluid friction. * See Ind. \& Eng. Chem., Oct., 1936, pp. 1229-34. " Combustion Qualities of Diesel Fuel,"
by G. D. Boerlage and J. J. Broeze. 
Bottling of Town's Gas for Use as Motor Fuel. (H. Wanser, Z. Rompr. Fluss Gase, 1936, 32, 6r-63. J. Soc. Chem. Ind. (Abstracts B), Vol. 56, Sept., 1937, p. 863.) (48/4I Germany.)

The compressibility coefficient $(C)$ of Berlin town gas has been calculated at $20^{\circ}$ over the range $5^{\circ}-35^{\circ} \mathrm{atm}$. from compressibility data available for the gas constituents. $C$ decreases with the pressure up to 85 atm., but steadily increases thereafter. Up to $206 \mathrm{~atm} . C$ is $\left\langle I\right.$; at $35^{\circ} \mathrm{atm} . C=\mathrm{I} . \mathrm{I}$ I9. Since a gas flask of I cu. m. capacity contains $89.5,206$ and $3^{\mathrm{I}} 3.5 \mathrm{cu} . \mathrm{m}$. of gas (referred to I atm., $20^{\circ}$ ) at 85,206 and $35^{\circ}$ atm., respectively, no advantage is gained by compressing above $35^{\circ}$ atm:

Changes in Lubricating Oil with Use. (H. Suida, Oel u. Kohle, I937, I3, 20I-206 and 225-32. J. Soc. Chem. Ind. (Abstracts B), Vol. 56, Sept., 1937, p. 87o.) (48/42 Germany.)

The ageing tendency of different oils can be followed only by determining all the decomposition products; a method by which this was effected for oils for use in a high pressure blower (using an auto-clave) is described. Oils of poor stability have a detrimental effect on the stability of stable oils with which they are mixed. The compounding of mineral oils with small amounts of fatty oils also very much decreases their stability to oxidation, and the incorporation of $\mathrm{Pb}$ soaps is preferred for heavy duty lubricants. Highly refined oils of high $H$ content are the most stable. Distillates are superior to residuals of the same $\eta$.

The Measurement of Air Speed in Flight. (F. L. Thompson, J. Aer. Sci., Vol. 4, No. Io, August, 1937, pp. 423-6.) (48/43 U.S.A.)

The measurement of air speed of aeroplanes by means of instruments attached to them is often very inaccurate. The sources of error are numerous and not all of them are easily avoided. It is the purpose of this paper to discuss the results of experience gained in numerous flight tests conducted at the laboratory of the N.A.C.A. at Langley Field. Two aspects of the problem are considered, one being the measurement of air speed with a high degree of precision using special test equipment, and the other being .the measurement of air speed with fair precision for normal flying. The latter aspect of the problem includes consideration of the provision of a satisfactory reference pressure for the altimeter. The use of a pitot static head is assumed throughout.

Time Lag in a Control System. (D. R. Hartree and A. Porter, Proc. Roy. Soc., Series A, Vol. I6I, No. 907, pp. 460-76.) (48/44 Great Britain.)

Previous work on the effect of a time lag on the operation of a control system is extended to a more general law relating the behaviour of the quantity controlled and the consequent operation of the control system. As before, the behaviour of the quantity controlled can be expressed in terms of the superposition of a set of damped harmonic " normal modes." Ranges of values of the control parameters which promise to give good control can be selected by inspection of contour diagrams giving the damping and frequency of one or two normal modes of lower frequency, and a closer examination of the behaviour of the control system with any set of parameters can then be made by the solution of the control equations on the differential analyser. A large number of such solutions has been carried out and an optimum set of control parameters is stated.

The modified control law appears to have some advantage over that previously investigated, from the points of view both of the kind of control obtainable and of the design and operation of the control gear.

A method of obtaining in practice a control law of the form studied is briefly indicated. 
The Design of Piezo Electric Indicators. (S. Meurer, Forschung, Vol. 8, No. 5, Sept.-Oct., 1937, pp. 249-60.) (48/45 Germany.)

For investigations on high speed internal combustion engines, a great deal depends upon the precision of pressure measurement if it is to be used as the basis for thermodynamical calculations. There are essentially three parts to the apparatus:- The crystal, the amplifier, and recorder. To obtain good results a high standard of precision is required in each of these component parts. The article deals, in particular, with the requirements of the crystal in order to avoid faults which may easily occur.

The Elastic Stability of a Long and Slightly Bent Rectangular Plate under Uniform Shear. (D. M. A. Leggett, Proc. Roy. Soc., Series A, Vol. I62, No. 908, I/9/37, pp. 62-82.) (48/46 Great Britain.)

A long plate, slightly curved, is subjected to a shearing force applied uniformly along its two straight edges. A theoretical investigation is carried out to ascertain the value of the shearing force at which buckling of the plate may be expected to take place.

Two cases are investigated, in one of which the two straight edges are simply supported, and in the other of which they are clamped. The results of the investigation, giving the critical shearing force in terms of the dimensions of the plate in each of the two cases considered, are shown graphically.

\section{The Use of Rubber in Vibration Isolation. (E. H. Hull, J. App. Mech., Vol. 4, No. 3, Sept., 1937, pp. A rog-1 14.) (48/47 U.S.A.)}

The desirable properties of an elastic material applicable to many types of vibration isolation problems are outlined. Of those materials at present available, rubber appears most suitable for this type of work. The general elastic properties of rubber are discussed and data given for determining the stiffness of pads made from one particular compound. Equations are developed for the six natural frequencies and associated modes of vibration of a mass supported on elastic pads and examples of vibration isolation worked out using this theory.

The Load Deflection Characteristics of Initially Curved Flexural Springs. (W. E. Johnson, J. App. Mech., Vol. 4, No. 3, Sept., 1937, pp. A I19i 27.) (48/48 U.S.A.)

The problem considered in this paper is that of determining the relation between the load and the deflection of a curved flexural member which is permitted to take large deflections, so that its action may be considered to be that of a spring. Four primary types of springs are considered, in each of which the line of action of the load is either perpendicular or parallel to the tangent to the neutral axis at the point of clamping. In addition to these, the equations for the initial curve of a piston ring with a large gap are given.

The results of the four primary types may be used for any spring which is a combination of several springs of one type, and also for combinations of different types. Thus a spring consisting of any portion of a circular arc may be analysed. Also the relations of load, deflection, and stress may be obtained for a spring consisting of several convolutions (corrugated), and subjected to either a compressive or extending force.

Torsion of Rectangular Tubes. (W. Hovgaard, J. App. Mech., Vol. 4, No. 3, Sept., 1937, pp. A 131-5.) (48/49 U.S.A.)

This paper is a report on experiments with the torsion of rectangular mild steel tubes undertaken to test the correctness of the now generally accepted theory of R. Bredt, based on a hydrodynamical analogy. The angles of torsion were determined, and the strains were measured with Huggenberger tensometers. While most of the strains were measured on the external surface of the tubes, 
internal strains were measured in one tube. The observed angles of torsion were found to be in fair agreement with theory, but the shearing stresses on the external surface were much higher and those on the internal surface much lower than the theoretical stresses. Breakdown of the tubes occurred while the theoretical shearing stress was still far below the yield point in shearing of the material. It appears that the theory does not give a true picture of the stress distribution after plastic flow has occurred at the re-entrant corners, and as this may happen very early, dependent on the radius of the fillets, the theory may in some cases lead to a dangerous over-estimate of the strength of such tubes.

\section{Miniature Ball Bearings. (Nature, Vol. 140, No. 3543, 25/9/37, pp. 539-40.) (48/50 Great Britain.)}

The new bearings vary in size from I to $22 \mathrm{~mm}$. overall diameter: They are thus suited for small motors, recorder clocks and other scientific instruments in which friction must be eliminated as far as possible. Comparative tests on these bearings and the jewelled bearings they are intended to replace show advantages under three different modes of operation:-

I. The time to damp down a rotary motion was eight times as long (plain pivots) and twenty times as long (tapered pivots).

2. For oscillatory motion the corresponding figures are 4 and $1_{5}$.

3 . In deviation tests the results were also favourable.

Contributions to the Theory of Incomplete Tension Bay. (E. Schapitz, L.F.F., Vol. 14, No. 3, 20/3/37, pp. 129-1 36. Translation in N.A.C.A. Tech. Memo. No. 831, July, 1937.) (48/5 I Germany.)

In a metal panel stressed simultaneously in shear and compression, the stress distribution immediately after buckling is still non-uniform and the second principal stress is not as yet negligible. This condition designated as " incomplete tension bay " is described by the present theory for the general case of combined stresses and elastically flexible stiffeners. The behaviour of the buckled plate is marked by two factors, one of which characterises the distribution of stress, the other the geometrical deformation which occurs with curved metal panels. The variation of the factors with the stresses and deformations must be obtained by experiments. The present report offers an approximate theory for the stress and deformation condition after buckling of the skin in reinforced panels and shells loaded in simple shear and compression and under combined stresses. The theory presents a unified scheme for stresses of these types; it is based upon the concept of non-uniform stress distribution in the metal panel and its marked power of resistance against compressive stresses (" incomplete" tension bay).

The Apparent Width of the Plate in Compression. (K. Marguerre, L.F.F., Vol. I4, No. $3,20 / 3 / 37$, pp. I $21-8$. Translation in N.A.C.A. Tech. Memo. No. 833, July, 1937.) (48/52 Germany.)

The present extension of the customary stability investigation to include the super-critical range proceeds in two steps. The first step considers the buckling form $w=f \cos \pi x / l \cos \pi y / b$ known from elementary theory, preserves the higher terms in $f$ and yields, with the aid of the principle of virtual displacements, a relation which gives the decrease of the apparent strain stiffness at the instant of buckling (analytically expressed " the tangent to the new stress-strain curve above the critical load").

The second step evolves on the basis of a formula containing several arbitrary values, from which the probably produced buckling form, with a greatly exceeded critical point, can be computed and which affords a stress strain curve which reproduces with sufficient agreement the actual conditions existing in a certain range. The apparent width is conveniently calculated within the cited range with the aid of formula which approximately comprise the result of the theory. 
The Stability of Orthotropic Elliptic Cylinders in Pure Bending. (O. S. Heck, L.F.F., Vol. 14, No. $3,20 / 3 / 37$, pp. I 37-147. Translation in N.A.C.A. Tech. Memo. No. 834, July,.. I937.) (48/53 Germany.)

The theoretical critical bending stress of elliptic cylindrical shells is determined on the assumption of infinite shell length and absence of local instability phenomena. The results of tests on isotropic elliptic cylindrical shells stressed in bending are compared with the theoretical results. The practical applicability of the theory is discussed.

How to Analyse the Contact Tooth Flanks of General Screw Gearings. (F. G. Altman, Forschung, Vol. 8, No. 5, Sept.-Oct., 1937, pp. 209-25.) (48/54 Germany.)

Up to now there is no method to analyse the contact of tooth flanks of screw gears, the wheels of which have no possibility of rolling upon each other, in contrast to worm gears. It is, however, impossible to determine the exact working conditions of these screw gears, or to develop them in the right way without having determined their conditions of contact and the formation of the lubricating film. The paper deals with this matter and shows how to determine details of the conditions of contact in a way suitable for the engineer.

The Magneto Elastic Properties of Steel and Their Application to Stress and Vibration Measurements. (S. Wintergeist, Forschung, Vol. 8, No. 5, Sept.-Oct., 1937, pp. 238-48.) (48/55 Germany.)

Stresses in parts of machines and structures are mostly determined by measuring the elongations. The apparatus for these purposes is not always applicable if the space is limited or if inertia prevents exact analyses of prevailing dynamic conditions.

The subject of the paper is the change of magnetic properties under stress, the so-called magneto elastic behaviour, and how this may be used for measurements of stresses.

Gas Flasks of Light Metals. (N: Christmann, Warme, 1936, 60, 236-7. J. Soc. Chem. Ind. (Abstracts B), Vol. 56, Sept., 1937, p. 863.) (48/56 Germany.)

Experience has shown that the internal and external varnish coatings for flasks made of lautal, bondur and duralumin should be applied after the official hydraulic pressure tests. The neck of the flask where the pressure-reducing valve is screwed in should be reinforced by shrinking on a steel collar.

Icing Measurements on Mount Washington. (S. Pagliuca, J. Aer. Sci., Vol. 4, No. Io, August, I937, pp. 399-402.) (48/57 U.S.A.)

This paper discusses experimental methods used on Mount Washington for the measurement of rime deposition and their possible application to the study of icing on aircraft. Investigations of rime deposition on Mount Washington were started last year for the purpose of classifying the phenomena. It soon became apparent that conditions were favourable for carrying out tests of icing of aircraft under natural conditions.

Rime forming fogs are very frequent. The average wind velocity is 40 m.p.h., with prolonged spells at Ioo m.p.h. The lowest temperature observed was $-47^{\circ} \mathrm{F}$. Preliminary experiments were carried out on a section of a metal wing installed $5 \mathrm{~m}$. above the ground. The model was free to adjust itself to the wind so that the leading edge was generally normal to and pointing into the wind. During the tests, the average temperature was $-12^{\circ} \mathrm{C}$, the specific humidity I.7 gm. $/ \mathrm{kg}$. and the average wind velocity $70 \mathrm{~m} . \mathrm{p} . \mathrm{ti}$. Under these conditions, 
The experiments are insufficient to draw any definite conclusion as to the proportion of hard and soft rime, but it is thought that the method will be able to yield useful information on the icing problem of aircraft.

Effect of Turbulence on the Propagation of Sound. (H. Lahl and O. Devik, Nature, Vol. I 39, No. 35 I7, pp. 550-1.) (48/58 Sweden.)

Sound intensity distribution measurements were carried out with sound emitters used for fog signalling purposes (frequency $300 / \mathrm{sec}$.). Although the wind was very slight, the curves of equal sound intensity. showed considerable distortion, and the intensity at a given place varied by as much as 5 to io phons over a period of three seconds, in spite of the fact that the emitter was very steady.

The authors account for the phenomena by: atmospheric turbulence, those turbulent " units" which have dimensions comparable with the wave length of the sound causing marked absorption.

It is suggested that by an analysis of the sound spectrum, data can be obtained both as to the amount of turbulence and the size of the "units."

A Photo-Electric Smoke Penetrometer. (A. S. G. Hill, J. Sci. Inst., Vol. I4, No. 9, Sept., I937, p. 296.) (48/59 Great Britain.)

The requirements of a method for determining rapidly the efficiency of filters which are used for the removal of particulate matter from gases are briefly discussed. A photo-electric photometric method for estimating the efficiency of filtering devices in terms of the percentage penetration of a standard testing cloud of carbon particles at a given rate of flow is described. Details are given concerning the apparatus and the manner in which it is operated.

The Sonic Altimeter for Aircraft. (N.A.C.A. Tech. Note No. 6I I, August, 1937.) (48/60 U.S.A.)

The general object of this report is to discuss the results already achieved with sonic altimeters in the light of the theoretical possibilities of such instruments. All the current instruments are described.

It appears that an altitude range from io to 800 feet can be covered satisfactorily by an installation weighing approximately 6 olb. These limits naturally depend on the intensity of the emitter, the noise level in the aircraft and the reflective power of the ground.

The table given below gives the estimated maximum altitude obtainable in an aeroplane at cruising speed under the best and worst atmospheric and ground conditions :-

$\begin{array}{ccc}\begin{array}{c}\text { Maximum } \\ \text { Best Conditions. }\end{array} & \begin{array}{c}\text { Altitude. } \\ \text { Worst Conditions. }\end{array} & \begin{array}{c}\text { Power of Emitter } \\ \text { (watts). }\end{array} \\ 500 & \text { I } 75 & 10 \\ 650 & 225 & 25 \\ 780 & 265 & 50 \\ 935 & 300 & 100 \\ \text { 1,025 } & 330 & 150 \\ \text { I, 300 } & 410 & 500\end{array}$

From this it appears that the economic limiting height for instruments of this type is approximately i, ooo feet ( 100 watt emitter). Seventy-five references.

Notes on Some Practical Comparison Tests Made Between Several Acoustic Measurement Methods. (E. T. Dickey, Proc. Inst. Rad. Eng., Vol. 25. No. 9, Sept., 1937, pp. I 136-52.) (48/6 I.U.S.A.)

In considering the various methods used in making over-all acoustic measurements on radio receivers, from the standpoint of possible standardisation, it was 
felt desirable to make a comparison of the results obtainable by the several principal methods now in use in the U.S.A. Accordingly a radio receiver was shipped successively to five different laboratories equipped to make such measureınents. It was checked between each shipment by a sixth laboratory to guard against changes caused by the shipments.

The test equipment set up and method used by each of the co-operation laboratories is described. The results obtained are discussed briefly and typical curves made by each laboratory are shown.

The author has refrained from drawing any arbitrary conclusions regarding the relative accuracy or effectiveness of the various test methods employed by the co-operating laboratories. Instead, the comments, which the engineers of each laboratory cared to make on the curves obtained and the methods used, have been given. The reader is thus. provided with data and a valuable series of comments from some of the most expert engineers in this field, from which he may arrive at his own conclusions.

In general it is felt that the curves show a greater degree of similarity than might have been expected considering the rather fundamental differences in the test methods used, and that certain possibilities in the direction of useful standardisation in this field have been indicated.

Electrical Character of the Spark Discharge of Automotive Ignition Systems.

(M. F. Peters, G. F. Blackburn and P. J. Hannen, J.S.A.E., Vol. 4I,

No. 3, Sept., 1937, papers in Digest, p. 29.) (48/62 U.S.A.)

Methods are given for measuring current and voltage during spark discharge in automotive ignition systems. Equations are developed which show the relation between voltage and current, and other equations are presented by means of which such quantities as frequency of the oscillations, decrement, resistance, and energy may be deduced from measurements made on an oscillogram.

The methods developed are applied to a typical ignition circuit. In the circuits used currents as high as 80 amp. at a frequency of about six megacycles were measured. The possibility of the occurrence of phenomena other than those recorded by the oscillograph is discussed briefly.

Radio Shielding. (H. E. Gray, J.S.A.E., Vol. 4I, No. 3, Sept., 1937, papers in Digest, p. 29.) (48/63 U.S.A.)

The general discussion presented in this paper includes shielded ignition systems, covering both high tension and low tension sides of the magneto, generators and generator control boxes, radio power units, motors for general service, and a résumé of aeroplane shielding and bonding practices.

On the Nature of Atmospherics. (R. A. Watson Watt, J. F. Herd and F. E. Lutkin, Proc. Roy. Soc., Series A, Vol. I62, No. 909, I5/9/37, pp. 267-85.) (48/64 Great Britain.)

The results of eye-and-hand delineations of atmospheric wave forms observed in the Red Sea and Indian Ocean, Egypt, the Anglo-Egyptian Sudan and in " control " observations in south-east England are presented in tabular form.

Photographic recording of wave form and of apparent direction of arrival at the two ends of a $560 \mathrm{~km}$. base line reveals the details of the dispersive process by which the higher frequency components, travelling with a higher group velocity and subject to heavier attenuation than the lower frequency components, form, at distances over some $500 \mathrm{~km}$., a discreet oscillatory component preceding and completely detached from a slow form of the type delineated by the eye-and-hand method. The principal characteristics of the resulting dual wave form are plotted against distance over ranges up to $4,000 \mathrm{~km}$. 
The Physical Reality of Space and Surface Waves in the Radiation Field of Radio Antenna. (K. A. Norton, Proc. Inst. Rad. Eng., Vol. 25, No. 9, Sept., I937, pp. I I92-1 202.) (48/65 U.S.A.)

Evidence is presented which indicates that, notwithstanding the change in sign made by Sommerfeld in his 1926 paper on radio wave propagation, the radiation field of a vertical electric dipole may be separated into space and surface wave components. Sommerfeld's original concepts as to the characteristics of two such waves in radio transmission are largely substantiated. It is shown that a space and a surface wave are generated by a simple vertical dipole antenna at the surface of the earth and that this surface wave has the same wave tilt as the Sommerfeld surface wave. Evidence is given which would indicate that this surface wave travels around the curve of the earth in much the same manner as a guided wire wave travels around a bend on a wire. In the appendix formulæ are given for the space and surface waves in the radiation fields of a horizontal electric dipole and of horizontal and vertical magnetic dipoles.

The Propagation of Radio Waves Over the Surface of the Earth and in the Upper Atmosphere. (K. A. Norton, Proc. Inst. Rad. Eng., Vol. 25, No. 9, Sept., 1937, pp. I 203-36.) (48/66 U.S.A.)

Complete general formulas are given for computing at any point above a plane earth of finite conductivity the vector electric field for a source which may be a combination of vertical and horizontal electric dipoles or a loop antenna with its axis parallel or perpendicular to the earth. As illustrations of the above general methods, formulæ are derived for the ground wave radiation from (I) a grounded vertical antenna carrying a sinusoidal current distribution and (2) elevated vertical and horizontal half wave antennæ. The "effective height" of the grounded vertical antenna is determined as a function of the ground constants, and this formula is then used to determine the effect of the ground constants on the ground wave field intensity in the neighbourhood of a quarter wave antenna. The formulæ are also used to show the influence of antenna height on the attenuation of high and ultra-high frequencies. The forward tilt, i.e., $E_{\mathrm{r}} / E_{\mathrm{z}}$, which occurs for the electric vector lying in the vertical plane passing through the antenna, is also easily computed from the formula given and is shown graphically. An expression for the Poynting vector is derived, and it is shown that a part of the energy in the wave near the ground flows downward into the ground. 